\title{
Polymer diodes with high rectification
}

L.S. Roman, Magnus Berggren and Olle Inganäs

\section{Linköping University Post Print}

N.B.: When citing this work, cite the original article.

Original Publication:

L.S. Roman, Magnus Berggren and Olle Inganäs, Polymer diodes with high rectification, 1999, Applied Physics Letters, (75), 3557-3557.

Copyright: American Institute of Physics (AIP) http://www.aip.org/

Postprint available at: Linköping University Electronic Press

http://urn.kb.se/resolve?urn=urn:nbn:se:liu:diva-32684 


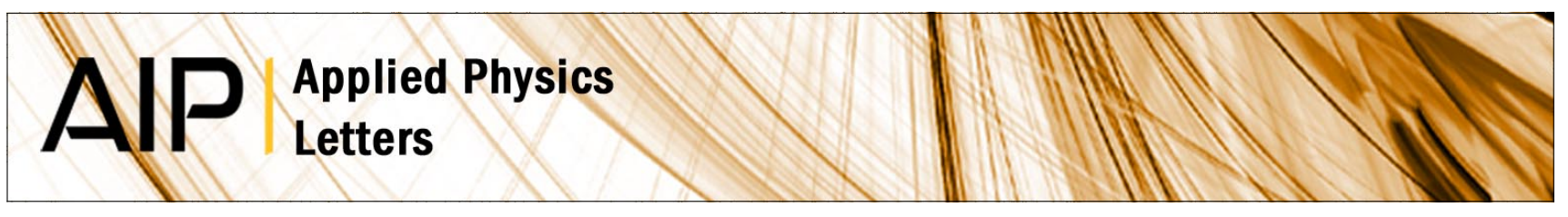

\section{Polymer diodes with high rectification}

L. S. Roman, M. Berggren, and O. Inganäs

Citation: Appl. Phys. Lett. 75, 3557 (1999); doi: 10.1063/1.125387

View online: http://dx.doi.org/10.1063/1.125387

View Table of Contents: http://apl.aip.org/resource/1/APPLAB/v75/i22

Published by the American Institute of Physics.

\section{Related Articles}

Rectifying behaviors induced by BN-doping in trigonal graphene with zigzag edges Appl. Phys. Lett. 100, 063107 (2012)

Three-dimensional shaping of sub-micron GaAs Schottky junctions for zero-bias terahertz rectification Appl. Phys. Lett. 99, 263505 (2011)

Rectifying characteristic of perovskite oxide La1.89Ce0.11CuO4/Ba0.5Sr0.5TiO3/La0.67Sr0.33MnO3 heterostructures

J. Appl. Phys. 110, 103716 (2011)

Thermal rectification in thickness-asymmetric graphene nanoribbons

Appl. Phys. Lett. 99, 193104 (2011)

Interface-dependent rectifying TbMnO3-based heterojunctions

AlP Advances 1, 042129 (2011)

\section{Additional information on Appl. Phys. Lett.}

Journal Homepage: http://apl.aip.org/

Journal Information: http://apl.aip.org/about/about_the_journal

Top downloads: http://apl.aip.org/features/most_downloaded

Information for Authors: http://apl.aip.org/authors

\section{ADVERTISEMENT}

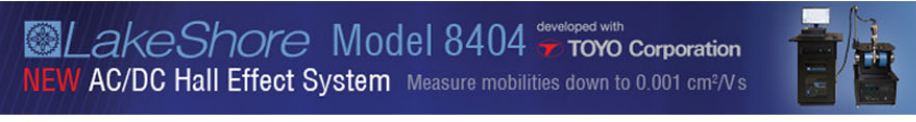




\title{
Polymer diodes with high rectification
}

\author{
L. S. Roman ${ }^{\text {a) }}$ \\ Laboratory of Applied Physics, Department of Physics, Linköping University, Linköping, S-58183, Sweden \\ M. Berggren \\ ITN, Campus Norrköping, Linköping University, Norrköping, S-60174, Sweden \\ O. Inganäs \\ Laboratory of Applied Physics, Department of Physics, Linköping University, Linköping, S-58183, Sweden
}

(Received 11 June 1999; accepted for publication 7 October 1999)

\begin{abstract}
Polymer diodes made using a bilayer of doped poly(3,4-ethylenedioxythiophene) and a semiconducting polymer in a sandwich structure with two low-work-function metals are reported. The conducting polymer layer acted as a modifier of the injection properties of the low-work-function metal, allowing easy hole injection. Upon insertion of the conducting polymer layer, the contact-limited current flow became bulk limited. With this anode, the fabrication of diodes with a rectification ratio of seven orders of magnitude was possible. We present patterned microdiodes made with crossing of $10 \mu \mathrm{m}$ lines, showing similar performance as the mm-size diode. (C) 1999 American Institute of Physics. [S0003-6951(99)04748-8]
\end{abstract}

A large effort towards fabrication of electronic devices using polymers ${ }^{1,2}$ is presently underway. Most of these studies concern field effect transistors and diodes, in imitation of silicon electronics. A high rectification organic diode is quite important for a broad spectrum of electronic applications. ${ }^{3}$ In order to fabricate diodes with high rectification, based on semiconducting polymers, one needs materials that allow efficient charge injection through the polymer under forward bias, and much less so under reverse bias. Normally this is achieved using materials that match in energy position, or make low potential barriers, to the energy levels of the polymer. In reverse bias both barriers for electrons and holes must be high enough to keep the current low, having thus as result a high rectification ratio. The quality of the polymer film formed onto a given electrode can also influence the diode properties. Polymer films spin coated onto inert materials such as gold often show pinholes by dewetting. These are not acceptable, when an upper electrode is evaporated on top of the polymer film in sandwich geometry. A solution to this problem is to introduce an additional polymer layer. A conducting/semiconducting polymer interface tends to have good performance and are extensively used to stabilize polymer light emitting diodes. We have used the conducting polymer poly(3,4-ethylenedioxythiophene (PEDOT) (PSS), and the semiconducting polymer, poly(2-methoxy, 5( 2 '-ethyl-hexyloxy)-1,4-phenylene vinylene) (MEH-PPV). PEDOT(PSS) was found to have a high work function value $5.2 \mathrm{eV}^{4}$ which allows efficient hole injection in light-emitting $\operatorname{diodes}^{5}$ (LEDs) or collection of holes in photodiodes. ${ }^{6,7}$ However, the higher resistivity of PEDOT(PSS), compared with ordinary metals, may cause unwanted voltage drop under large currents. A metal layer under the polymer is used to make a high conductance line.

Diodes made with several metals of varying work function $[\mathrm{Al}(4.2 \mathrm{eV}), \mathrm{Ag}(4.3 \mathrm{eV}), \mathrm{Cu}(4.5 \mathrm{eV})]$ were tested. In all

${ }^{a)}$ Electronic mail: lucimara@ifm.liu.se cases, the current flow of holes that was contact limited ${ }^{8}$ changed to bulk limited when PEDOT(PSS) was used in between the anode metal and MEH-PPV. We choose to study copper metal due to the good stability and ease of patterning. The $\mathrm{Cu} / \mathrm{PEDOT}(\mathrm{PSS})$ interface is ohmic, important for its use as an electrode in diodes. The contact resistance $\left(r_{c}\right)$ was measured using a planar geometry where four parallel stripes of $\mathrm{Cu}$ were evaporated onto a glass substrate. The PEDOT(PSS) (Baytron P, Bayer AG) layer, was deposited by spin casting from a 30\% isopropanol/water solution, filtered using $1 \mu \mathrm{m}$ pore size glass filter. The film was annealed during $5 \mathrm{~min}$ in $120^{\circ} \mathrm{C}$, in order to remove remaining water in the film. With the $\mathrm{Cu}$ stripes as contacts, we obtain the current-voltage $(I-V)$ characteristics of the polymer film between the inner lines. The resistance value of the polymer film was measured by four-probe technique. From the relation $V / I=2 r_{c}+R$, where $R$ is the resistance of the polymer film, $V$ is the voltage and $I$ is the current, we obtain the contact resistance value $\left(r_{c}\right)$. We convert this using the area of contact, and find a contact resistance value $\sim 7 \Omega / \mathrm{mm}^{2}$ for the $\mathrm{Cu} / \mathrm{PEDOT}$ (PSS) interface.

The diodes were constructed in sandwich geometry using $\mathrm{Cu} / \mathrm{PEDOT}(\mathrm{PSS})$ as the anode and $\mathrm{Al}$ as the cathode. They were mounted onto glass or $\mathrm{Si} / \mathrm{SiO}_{2}$ substrates. $\mathrm{Cu}$ was deposited by evaporation onto half part of the substrate for the large diodes $\left(6-10 \mathrm{~mm}^{2}\right)$. The PEDOT (PSS) layer was deposited by spin coating as above, and patterned on top of the $\mathrm{Cu}$. We notice that the PEDOT(PSS) solution etches the surface of $\mathrm{Cu}$, which eases formation of the contact. The polymer MEH-PPV was deposited by spin casting from a chloroform solution to a thickness of $190 \mathrm{~nm}$. The upper electrode, $\mathrm{Al}$, was vacuum evaporated through a shadow mask. For diodes with $100 \mu \mathrm{m}^{2}$ of active area the construction followed the patterning steps common in the $\mathrm{Si}$ technology. ${ }^{9}$ The processing includes patterning of $\mathrm{Cu}$ layer with PEDOT(PSS) on top in 500- $\mu \mathrm{m}$-long stripes of width $10 \mu \mathrm{m}$, followed by the annealing treatment. This patterned substrate was covered with MEH-PPV and Al was sputtered 


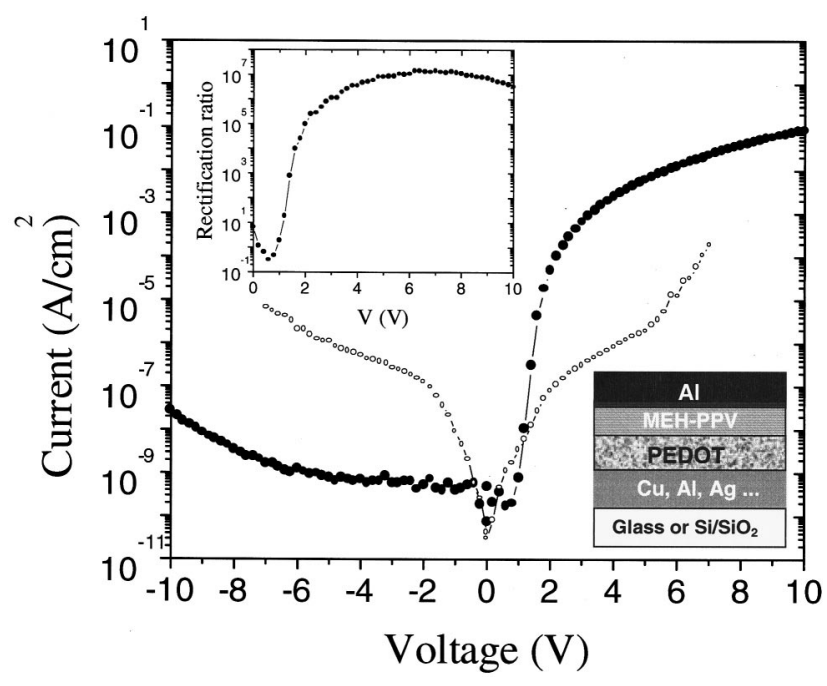

FIG. 1. Semilog plot of the current-voltage characteristics of two similar MEH-PPV based diodes using different anodes $\mathrm{Cu}$ (open circles) and $\mathrm{Cu} /$ PEDOT(PSS) (solid circles). The inset graph shows a semilog plot of the rectification ratio vs voltage for the $\mathrm{Cu} / \mathrm{PEDOT}(\mathrm{PSS})$ anode diode. The diodes used were fabricated in sandwich structure $\mathrm{Cu} / \mathrm{PEDOT}(\mathrm{PSS}) / \mathrm{MEH}-$ PPV/Al, the inset presents the sequence of layers, besides $\mathrm{Cu}$ any other metal could be used.

on top and patterned in order to make intersections of $100 \mu \mathrm{m}^{2}$.

The $J(V)$ characteristics of diodes with and without the PEDOT layer are very different (Fig. 1). The measurements were performed in the dark, using a Hewlett Packard 4156A parameter analyzer. The almost symmetric $J(V)$ shape is converted to a diode behavior after inclusion of the PEDOT(PSS) layer. Due to the higher value of the work function of PEDOT(PSS), compared to $\mathrm{Cu}$, the energy barrier for hole injection from PEDOT(PSS) to the MEH-PPV is $\varphi$ $\cong 0.1 \mathrm{eV}$, much smaller than from $\mathrm{Cu}$ to MEH-PPV which is $\varphi \cong 0.8 \mathrm{eV} ;{ }^{10}$ therefore the current injection in these two situations are different. With the $\mathrm{Cu}$ electrode we have a contact limited current regime; in this low injection regime the current densities are small and space charge effects can be neglected. With the inclusion of a thin layer of PEDOT(PSS), we go to a bulk limited current regime, where the forward current is mostly due to the positive carriers coming from the $\mathrm{Cu} / \mathrm{PEDOT}(\mathrm{PSS})$ electrode. The Cu/PEDOT(PSS)/ MEH-PPV/Al diodes show a $J(V)$ characteristic with three limiting regions. From 0 to $1 \mathrm{~V}$ the current is at the noise level of the equipment; little charge flow occurs. This condition is due to the difference in the work function values of the electrodes [between PEDOT(PSS) and $\mathrm{Al} \cong 1 \mathrm{eV}$ ] which creates an inherent potential ${ }^{11}$ into the polymer layer that opposes hole injection. One has to apply a higher voltage in order to inject charge. Between 1 and $2 \mathrm{~V}$ the current has an exponential behavior, and increases five orders of magnitude. This dramatic increase is due to the interface PEDOT(PSS)/ MEH-PPV, with a low energy barrier. Beyond $2 \mathrm{~V}$ the current becomes dependent on the transport properties of the MEH-PPV layer. This behavior of the current density is consistent with the capacitance-voltage $(C-V)$ characteristics measured on these devices. The $C-V$ measurements were performed using Auto Lab frequency response analyser (Eco Chemie) in dark environment at $50 \mathrm{~Hz}$ frequency. For diodes with $\mathrm{Cu}$ anode the capacitance presented a constant value in

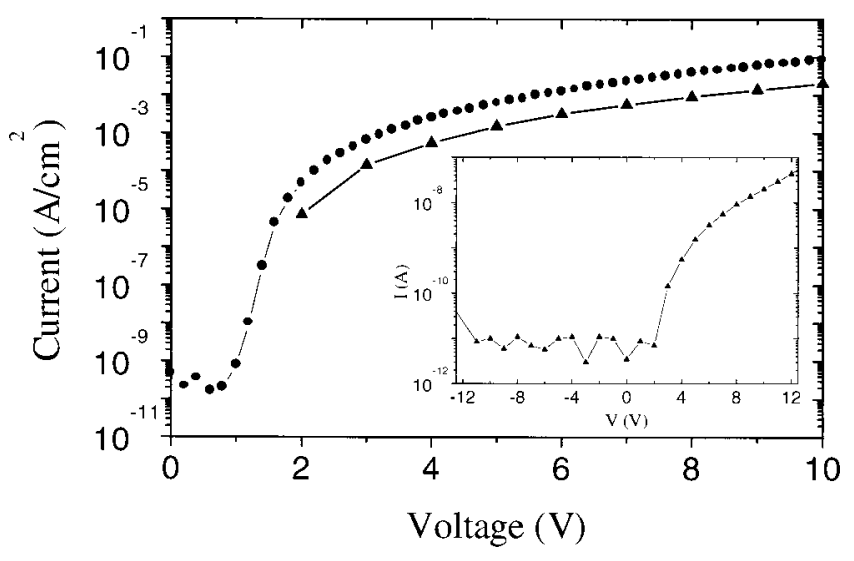

FIG. 2. Scaling the forward current density of a Cu/PEDOT(PSS)/MEHPPV/Al $100 \mu \mathrm{m}^{2}$ diode (solid triangles) with the forward current density of the diode presented in Fig. 1. The inset presents a semilog plot of the current-voltage characteristics of the $100 \mu \mathrm{m}^{2}$.

the range of -5 to $+5 \mathrm{~V}$, but for the diodes with $\mathrm{Cu} /$ PEDOT(PSS) anode the capacitance value was constant from negative bias until around $2.5 \mathrm{~V}$ when it started to increase continuously until $5 \mathrm{~V}$, when the capacitance was double the initial value. At $3 \mathrm{~V}$ we have six orders of magnitude rectification, increasing to seven orders between 4 and $8 \mathrm{~V}$ (Fig.1, inset). After $8 \mathrm{~V}$ the injection of holes from $\mathrm{Al}$ to MEH-PPV increases the reverse current, and thus decreases the rectification value.

Diodes of $100 \mu \mathrm{m}^{2}$ active area have similar shape of the $J(V)$ characteristics (inset Fig. 2). The shift in the absolute value of the current density can be due to a thickness difference between the diodes. In the small diodes, the side is $\sim 100$ times the thickness of the layers. Fringe fields are expected to become important in smaller diodes; even more important may be irregularities causing our geometrical estimates to err.

The electrical transport properties of conjugated polymers and polymer/metals junctions has been studied for quite some time, and the first attempt in modeling the PPV based diodes were based on the Fowler-Nordheim model describing the tunneling process in the diode, thus allowing extraction of values for barrier heights ${ }^{12}$ and for the polymer energy levels. ${ }^{13,14} \mathrm{~A}$ number of models have since been presented, taking into account more parameters or detailing the interface properties. ${ }^{715-18}$ It was suggested that when the current is limited by the contact it can be determined by the image force, ${ }^{15,16}$ the effect of Coulomb trapping of carriers at the interface. This trapping results in an increase of the energy barrier height, decreasing the injection. It was concluded that the presence of an insulating material free of traps could increase the charge injection..$^{15}$ It was shown that upon deposition of PEDOT(PSS) by spin coating, a segregation of PEDOT and PSS ${ }^{4}$ occurs. PSS is an insulating material and it was found forming a thin layer over the PEDOT film. This thin layer cannot trap charges from the electrode, which may help in the improvement of carrier injection from PEDOT at low bias. The bulk limited current of MEH-PPV has been studied and reported by several research groups, ${ }^{9,19,20}$ where at high fields MEH-PPV presents a space charge limitation of the current, and the mobility is dependent on the applied electric field. In our case the behavior is 


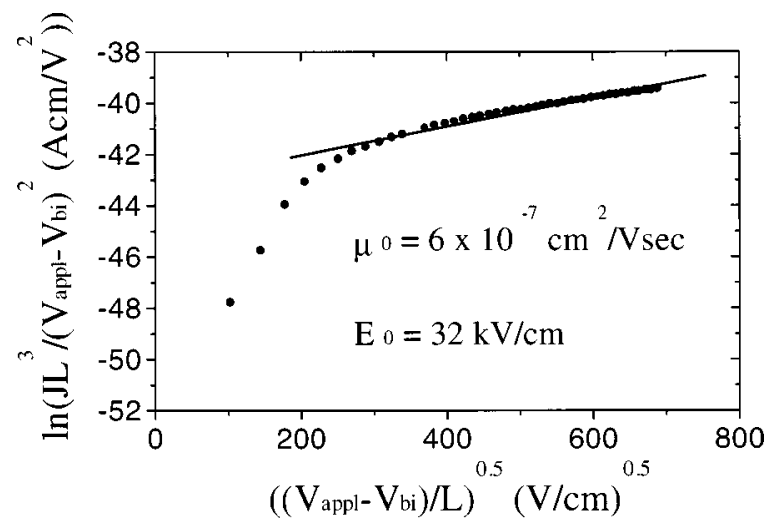

FIG. 3. Current-voltage characteristics of $\mathrm{Cu} / \mathrm{PEDOT}(\mathrm{PSS}) / \mathrm{MEH}-\mathrm{PPV} / \mathrm{Al}$ device (Fig. 1) plotted in the format $\ln \left(J L^{3} / V^{2}\right)$ vs $(V L)^{0.5}$, where $J$ is the current density, $L$ is the polymer thickness, and $V$ the applied voltage decreased of the built in voltage.

similar, and the current does not depend strictly on $V^{2}$ because of the field dependent mobility. Recent work $^{21}$ suggested the use of a model developed by Murgatroyd ${ }^{22}$ that combines space charge limitation dependence with the field dependent mobility in the same equation. From this model we can evaluate our data by plotting the high field current in the equations format $\ln \left(J L^{3} / V^{2}\right)$ vs $(V L)^{0.5}$ (Fig. 3). We were able to fit our data and get parameters such as the zero field mobility, $\mu_{0}=6 \times 10^{-7} \mathrm{~cm}^{2} / \mathrm{V} \mathrm{s}$ and the characteristic field, $E_{0}=32 \mathrm{kV} / \mathrm{cm}$, similar to previously reported values.

In summary, we have demonstrated a high-rectification polymer diode using two low-work-function metals, where the anode was modified by the introduction of a conductingpolymer layer, PEDOT(PSS). This surface modification takes us from a low-injection contact-limited current to bulklimited current. The PEDOT/PSS segregation might add to the charge injection by avoiding trapping at the interface due to the image force effects. The possibility of making these diodes patterned on a micrometer scale has been demonstrated.
The authors acknowledge fruitful discussions with G. Gustafsson, J. Carlsson, and G. Gudesen and financial support from Opticom ASA.

${ }^{1}$ Z. Bao, A. Dodabalapur, and A. J. Lovinger, Appl. Phys. Lett. 69, 4106 (1996).

${ }^{2}$ H. Sirringhaus, N. Tessler, and R. H. Friend, Science 280, 1741 (1998).

${ }^{3}$ D. Brawn and A. J. Heeger, Appl. Phys. Lett. 58, 1982 (1991); G. Yu et al., Appl. Phys. Lett. 68, 1540 (1994).

${ }^{4}$ G. Greczynski, Th. Kugler, and W. R. Salaneck, Thin Solid Films (in press).

${ }^{5}$ Y. Cao, G. Yu, C. Zhang, R. Menon, and A. J. Heeger, Synth. Met. 85, 1397 (1997).

${ }^{6}$ L. S. Roman, W. Mammo, L. A. A. Pettersson, M. R. Andersson, and O. Inganäs, Adv. Mater. 10, 774 (1998).

${ }^{7}$ A. C. Arias, M. Granström, D. S. Thomas, K. Petritsch, and R. H. Friend, Phys. Rev. B 60, 1854 (1999).

${ }^{8}$ B. K. Crone, I. H. Campbell, P. S. Davis, and P. L. Smith, Appl. Phys. Lett. 73, 3162 (1998).

${ }^{9}$ Private communication from IMC.

${ }^{10}$ I. H. Campbell, P. S. Davis, D. L. Smith, N. N. Barashkov, and J. P. Ferraris, Appl. Phys. Lett. 72, 1863 (1998)

${ }^{11}$ G. Malliaras, J. R. Salem, P. J. Brock, and J. C. Scott, J. Appl. Phys. 84, 1583 (1998).

${ }^{12}$ I. D. Parker, J. Appl. Phys. 75, 1656 (1994).

${ }^{13}$ I. A. Hümmelgen, L. S. Roman, F. C. Nart, L. O. Péres, and E. L. de Sá, Appl. Phys. Lett. 68, 3194 (1996).

${ }^{14}$ L. S. Roman, I. A. Hümmelgen, F. C. Nart, L. O. Péres, and E. L. de Sá, J. Chem. Phys. 105, 10614 (1996).

${ }^{15}$ M. Koehler and I. A. Hümmelgen, Appl. Phys. Lett. 70, 3254 (1997).

${ }^{16}$ E. M. Conwell and M. W. Wu, Appl. Phys. Lett. 70, 1867 (1997).

${ }^{17}$ M. N. Bussac, D. Michoud, and L. Zuppiroli, Phys. Rev. Lett. 81, 1678 (1998).

${ }^{18}$ M. Koehler and I. A. Hümmelgen, Interface Sci. 6, 235 (1998).

${ }^{19}$ P. W. Blom, M. J. M. de Jong, and J. J. M. Vleggar, Appl. Phys. Lett. 68, 3308 (1996)

${ }^{20}$ L. Bozano, S. A. Carter, J. C. Scott, G. G. Malliaras, and P. J. Brock, Appl. Phys. Lett. 74, 1132 (1999).

${ }^{21}$ G. G. Malliaras, J. R. Salem, P. J. Brock, and C. Scott, Phys. Rev. B 58, R13411 (1998).

${ }^{22}$ P. N. Murgatroyd, J. Phys. D 3, 151 (1970). 